Journal

of

Insect

Physiology

www.elsevier.com/locate/jinsphys

\title{
Influence of dietary nutritional composition on caterpillar salivary enzyme activity
}

\author{
Branislav Babic $^{\mathrm{a}}$, Alexandre Poisson ${ }^{\mathrm{a}}$, Shireef Darwish ${ }^{\mathrm{a}}$, Jean Lacasse ${ }^{\mathrm{a}}$, \\ Magali Merkx-Jacques $^{\mathrm{a}}$, Emma Despland ${ }^{\mathrm{b}}$, Jacqueline C. Bede ${ }^{\mathrm{a}, *}$ \\ a Department of Plant Science, McGill University, 21,111 Lakeshore, Ste-Anne-de-Bellevue, Québec, Canada H9X 3 V9 \\ ${ }^{\mathrm{b}}$ Biology Department, Concordia University, 7141 Sherbrooke St. W., Montréal, Québec, Canada H4B 1 R6
}

Received 26 June 2007; received in revised form 19 September 2007; accepted 28 September 2007

\begin{abstract}
Caterpillars are faced with nutritional challenges when feeding on plants. In addition to harmful secondary metabolites and proteinand water-limitations, tissues may be carbohydrate-rich which may attenuate optimal caterpillar performance. Therefore, caterpillars have multiple strategies to cope with surplus carbohydrates. In this study, we raise the possibility of a pre-ingestive mechanism to metabolically deal with excess dietary sugars. Many Noctuid caterpillars secrete the labial salivary enzyme glucose oxidase (GOX), which oxidizes glucose to hydrogen peroxide and gluconate, a nutritionally unavailable carbohydrate to the insect. Beet armyworm, Spodoptera exigua, larvae were restricted to diets varying in protein to digestible carbohydrate (P:C) ratio $(42 \mathrm{p}: 21 \mathrm{c} ; 33 \mathrm{p}: 30 \mathrm{c} ; 21 \mathrm{p}: 42 \mathrm{c})$ and total nutrient concentration (42\% and 63\%). High mortality and longer developmental time were observed when caterpillars were reared on the C-biased, P-poor diet (21p:42c). As the carbohydrate content of the diet increased, caterpillars egested excess glucose and a dietdependent difference in assimilated carbohydrates and pupal biomass was not observed, even though caterpillars restricted to the C-biased diet (21p:42c) accumulated greater pupal lipid reserves. Larval labial salivary GOX activity was also diet-dependent and gluconate, the product of GOX activity, was detected in the frass. Unexpectedly, GOX activity was strongly and positively correlated with dietary protein content.
\end{abstract}

(C) 2007 Elsevier Ltd. All rights reserved.

Keywords: Larval performance; Salivary enzymes; Nutritional quality; Spodoptera exigua

\section{Introduction}

Invertebrate herbivores, particularly generalists, face dietary nutritional variation in plants, in terms of species, developmental stage and tissues and responses to the environment (Bae and Sicher, 2004; Cross et al., 2006; Mattson, 1980; Roberts and Paul, 2006; Roslin et al., 2006; Yeoh et al., 1992). The proper feeding decision is critical and can greatly impact herbivore growth, development and reproductive success (Auger, 1995; Awmack and Leather, 2002; Barton-Browne, 1993). Therefore, caterpillars must be able to monitor their nutrient intake and often have behavioral and/or biochemical mechanisms to cope with non-ideal foods (Bede et al., 2007; Behmer et al., 2002;

\footnotetext{
${ }^{*}$ Corresponding author. Tel.: + 15143987860 ; fax: + 15143987897.

E-mail address: jacqueline.bede@mcgill.ca (J.C. Bede).
}

Raubenheimer and Simpson, 2003; Simpson and Simpson, 1990; Waldbauer and Friedman, 1991). One such mechanism may be to switch food sources (Behmer et al., 2002; Bernays et al., 2004; Hägele and Rowell-Rahier, 1999; Moreau et al., 2003; Wright et al., 2003). Although caterpillars are relatively mobile (McAuslane and Alborn, 2000; Smits et al., 1987) and may, within one or amongst closely neighboring plants, find dietary variation between protein-rich reproductive tissues and carbohydrate-rich leaves (Cross et al., 2006; Mattson, 1980; Roulston et al., 2000), caterpillars are often restricted to nutritionally unbalanced diets and, presumably, have mechanisms to cope with nutrient variation.

Dietary proteins $(\mathrm{P})$ and digestible carbohydrates $(\mathrm{C})$ and, in particular, the ratio of these two nutrients $(\mathrm{P}: \mathrm{C})$ are critical for proper insect growth and development (Simpson and Raubenheimer, 1993). Generalist caterpillars often 
select and perform better on a slightly P-biased diet (Lee et al., 2006, 2002; Merkx-Jacques et al., in press; Waldbauer et al., 1984). However, plants, particularly forbs, are rich in digestible mono- and disaccharide carbohydrates and are relatively nitrogen-limited (Mattson, 1980; National Research Council, 2001; Scriber and Slansky, 1981), which may negatively impact caterpillar growth and development (Felton, 1996; Karowe and Martin, 1989; Lee et al., 2002, 2003; Merkx-Jacques et al., in press; Raubenheimer et al., 2005). Not only are plants often P-limited, but in response to herbivory, they often have strategies to obstruct protein digestion by the caterpillar such as inducible proteinase inhibitors and amino acid deaminases that specifically degrade essential amino acids in the caterpillar midgut (Chen et al., 2005; Kang et al., 2006; Ryan, 1990). On these P-poor diets, many caterpillar species engage in compensatory feeding (Raubenheimer et al., 2005; Simpson et al., 2004; Warbrick-Smith et al., 2006), exposing them to even greater $\mathrm{C}$ excesses and more noxious plant secondary metabolites. For many insect species, the necessity to achieve the optimal balance of dietary P:C results in tradeoffs between growth (protein) and accumulating sufficient lipid stores (carbohydrate) for adult requirements, such as migration and oogenesis (Awmack and Leather, 2002; Lee et al., 2004a; Simpson and Raubenheimer, 1993).

Caterpillars have strategies to cope with dietary C excesses. On a daily basis, caterpillars are assumed to manage surplus dietary sugars by lowering their C utilization efficiency or increasing $\mathrm{C}$ egestion, lipid stores, or metabolic respiration (Simpson and Simpson, 1990; Telang et al., 2003; Zanotto et al., 1997). Adaptation to excess dietary $\mathrm{C}$ is so critical that generalist caterpillars of Plutella xylostella show generational plasticity, which may come at a fitness cost (Warbrick-Smith et al., 2006).

Another strategy to cope with nutritional imbalances is to metabolize nutrients before ingestion by secreted salivary enzymes. Differential salivary digestion has been observed for the desert spider, Stegodyphys lineatus, where nutrients were differentially extracted from their prey (Mayntz et al., 2005). During the feeding process, caterpillars secrete saliva onto the plant (Ribeiro, 1995) to digest and transport chewed plant tissue into their buccal cavity. In addition to aiding digestion, salivary enzymes may detoxify noxious plant secondary metabolites or, as is proposed in this paper, help to regulate nutrient levels in the plant before ingestion. Many Noctuid caterpillars, including Spodoptera exigua, Helicoverpa armigera, Helicoverpa assulta and Helicoverpa zea possess the salivary enzyme glucose oxidase (GOX) (Eichenseer et al., 1999; Merkx-Jacques and Bede, 2005; Zong and Wang, 2004), which catalyzes the oxidation of glucose to hydrogen peroxide and gluconate, which to the insect is a dietary unavailable form of carbohydrate. A number of roles for caterpillar salivary GOX have been proposed (Eichenseer et al., 1999; Musser et al., 2002, 2005a, b). The hydrogen peroxide produced by this enzyme may act as a signaling molecule and interfere with induced plant defensive pathways that are induced in response to caterpillar herbivory (Bede et al., 2006; Musser et al., 2002, 2005a) or an antimicrobial agent (Musser et al., $2005 \mathrm{~b}$ ). The consumption of oxygen by the reaction may help maintain an anaerobic midgut which would lower the reactivity of plant compounds, such as phenolics and tannins in the ingested leaves (Eichenseer et al., 1999). We propose that, in addition, salivary GOX may be a preingestive way for the caterpillar to cope with dietary $\mathrm{C}$ excesses since by metabolizing glucose to gluconate, caterpillars may dispose of excess dietary sugars in nutritionally imbalanced diets.

Caterpillar salivary GOX activity is diet-dependent in $S$. exigua caterpillars (Merkx-Jacques and Bede, 2005). When caterpillars are transferred from the legume, Medicago truncatula, to a wheat germ-based artificial diet, salivary GOX activity significantly increases (Merkx-Jacques and Bede, 2005). Peiffer and Felton (2005) also noted that caterpillar salivary GOX is affected by plant diet; enzyme activity decreases as plant nutritional quality increases.

In this study, we wished to determine if caterpillar salivary GOX could be a pre-ingestive mechanism to cope with dietary $\mathrm{C}$ excesses which allows these caterpillars to achieve optimal performance on C-biased diets. Previous studies have shown that when given choices, $S$. exigua caterpillars select a diet with a intake target of 22p:20c (Merkx-Jacques et al., in press). As noted in other Lepidopteran species, when $S$. exigua caterpillars are restricted to a C-rich, P-poor diet, high mortality and delayed development are observed (Lee et al., 2002, 2003, 2004a). However, in contrast to related Spodoptera species, higher pupal lipid reserves and biomass was not observed in $S$. exigua caterpillars reared on C-biased diets (Karowe and Martin, 1989; Lee et al., 2002, 2004a). Therefore, $S$. exigua caterpillars exhibit flexible and efficient preingestive nutrient intake regulation and post-ingestive utilization and we wished to determine if salivary GOX is a possible mechanism involved in this nutrient balancing.

To answer this, $S$. exigua caterpillars were restricted to chemically defined diets ranging in their P:C ratio over their development from 3rd larval instars to pupation. These diets only contained glucose as their digestible carbohydrate source. Larval stadium duration, mortality and pupal biomass, indicators of caterpillar performance, were assessed. Carbohydrates egested in the frass (including glucose and gluconate) as well as those converted to lipid stores in the pupa were measured to determine possible mechanisms of carbohydrate metabolism. Salivary GOX activity in actively feeding 4th instar caterpillars was also examined to see if diet affected enzyme activity.

\section{Materials and methods}

\subsection{Caterpillar colony}

Eggs of the beet armyworm, S. exigua (Hübner) (Lepidoptera: Noctuidae) were obtained from AgriPest 
Inc. (Zebulon, NC). The laboratory colony was reared for multiple generations on an artificial wheat germ-based diet (Bio-Serv, Frenchtown, NJ) in a growth chamber (16:8 light:dark hours; $28-40 \%$ relative humidity; $28.5^{\circ} \mathrm{C}$ ). Adult moths were allowed to mate and collected eggs were used to maintain colony.

\subsection{Defined synthetic diet}

Chemically defined artificial diets were prepared according to Simpson and Abisgold (1985). All ingredients were obtained from Bio-Serv unless otherwise indicated. Four diets were prepared containing different ratios of protein:digestible carbohydrates: 21p:42c, 22p:20c, 33p:30c, 42p:21c. Amino acid and protein sources were casein (bovine milk; Bio-Serv), peptone (Sigma) and albumen (egg white; Bio-Serv) in a 3:1:1 ratio. According to Lee et al. (2003), the amino acid composition of this preparation is similar to wheat seedlings. The digestible carbohydrate source was glucose (Sigma). As a non-digestible component, cellulose was used as a bulking agent to maintain the correct nutritive concentration in the diets. Standard constituents of all diets were: cholesterol $(0.55 \%)$ which was solubilized in linseed oil (linoleic acid, $0.5 \%$ ), Wesson's salts $(2.5 \%$; Sigma), ascorbate (1\%; Sigma), choline chloride $(0.5 \%$; Sigma), sorbic acid $(0.5 \%$; Sigma $)$, methyl paraben $(0.35 \%)$, and vitamin supplement $(0.06 \%)$. Ingredients for the vitamin mix were all obtained from Sigma, unless otherwise indicated. The vitamin supplement was a preparation of thiamine $(4.75 \%)$, riboflavin $(4.75 \%)$, nicotinic acid $(19.01 \%)$, pyridoxine $(4.75 \%)$, folic acid $(4.75 \%)$, myo-inositol $(47.53 \%)$, calcium panthothenate $(9.51 \%), p$-aminobenzoic acid $(4.75 \%)$ and biotin $(0.19 \%)$ (Bio-Serv). The diet was suspended in a $2 \%$ agar solution.

\subsection{Experimental rearing}

Fragile first instar caterpillars were allowed to feed upon the wheat germ-based Bio-Serv diet until they moulted to 2nd instars at which point they were individually placed on weighed blocks of diet $(1.3 \mathrm{~g})$ in Petri dishes lined with sterile paper towels. For each diet, the performance of 16 caterpillars was evaluated and the experiment was repeated. Petri dishes were closed using Parafilm to prevent water loss and placed in a growth chamber (16:8 light:dark hours; $\left.28.5^{\circ} \mathrm{C}\right)$. Small blocks of diet were changed as needed (approximately every 3 days) and never allowed to dry or be eaten completely. Caterpillars were left to feed until pupation. Caterpillar developmental stage was recorded every $12 \mathrm{~h}$ until pupation. Twelve hours after pupation, frass and remaining diet were collected, ovendried and weighed to the closest $0.1 \mathrm{mg}$. In addition, the sex of the insects was ascertained. Pupae were lyophilized until a constant weight was reached and weighed. Throughout the experiment, when blocks of food were added, frass and uneaten diet was collected, oven-dried and weighed.
Ten pre-weighed blocks of food for each treatment were oven-dried and weighed to the closest $0.1 \mathrm{mg}$. A linear regression of fresh weight (FW) vs. dry weight (DW) was used to determine the initial dry weight of the blocks fed to the caterpillars and to calculate dry weight food consumption.

\subsection{Pupal lipid extraction}

Lipids were extracted from dried pupa as described by Zera et al. (1994). Briefly, individual pupae were ground using a glass homogenizer. Lipids were extracted in a $2: 1$ mixture of methanol:chloroform containing $0.05 \%$ butylated hydroxytoluene (BTH). After $24 \mathrm{~h}$, the methanol:chloroform BTH was removed and new organic solvent added to the pupa. This was repeated three times. Supernatants were pooled and then washed with a $0.88 \%$ $\mathrm{KCl}$ solution $(\mathrm{w} / \mathrm{v})$. After evaporation of the solvents, samples were weighed to determine the lipid stores.

\subsection{Sex determination}

The genital aperture on the ventral side of the pupa was examined to determine insect sex (Scoble, 1992).

\subsection{Frass carbohydrates}

Glucose (Sigma) and gluconate (Megazyme) levels were determined in the caterpillar frass according to manufacturer instructions and modified for a 96-well plate format. D-Glucose levels were specifically measured spectrophotometrically using a GOX/peroxidase-o-dianisidine coupled reaction (Sigma). A standard curve was prepared from a NIST standard glucose solution. All frass samples were assayed in triplicate. An experimental control without frass (blank) was included. D-Gluconate $/ \delta$-glucono- $\delta$-lactone levels were specifically measured by a 6-phosphogluconate dehydrogenase/gluconate kinase assay (Megazyme). Changes in NADPH levels were measured spectrophotometrically. Gluconate standard curve and all frass samples were assayed in triplicate and an experimental control without frass (blank) was also included.

Calculations of carbohydrate assimilation were estimated from the amount of glucose ingested (see Section 2.3) minus the glucose and gluconate detected in the frass.

\subsection{Caterpillar salivary glucose oxidase (GOX) activity}

\subsubsection{Experiment 1}

Since the hypothesis being tested was that caterpillar salivary GOX is a pre-ingestive mechanism to deal with excess dietary carbohydrates, caterpillars were reared from eggs on a slightly P-biased diet, 22p:20c, which had low carbohydrate levels to ensure that they had minimal background GOX activity. Third instar caterpillars were individually restricted to chemically defined foods (21p:42c, 22p:20c, 33p:30c, 42p:21c). In this first experiment, cater- 
pillars were left on these diets for as long as possible (approximately $72 \mathrm{~h}$ ) to ensure that they had time to adjust their salivary GOX activity to the diet. Labial salivary glands were dissected from mid-5th instar caterpillars and assayed for GOX activity. A diet-dependent difference in mass of the caterpillars used in this experiment was not observed (average mass $\left.=0.47 \pm 0.02 \mathrm{~g} ; F_{(3,23)}=0.53, p=0.67\right)$. Cold-anesthetized caterpillars were placed ventral side up and rinsed with cold, sterile Nathanson's saline $(150 \mathrm{mM} \mathrm{NaCl}, 3 \mathrm{mM} \mathrm{KCl}$, $3 \mathrm{mM} \mathrm{CaCl}, 10 \mathrm{mM}$ TES, $20 \mathrm{mM} \mathrm{MgCl}, \mathrm{pH}$ 6.9; Christensen et al., 1991) to remove any debris or frass. The head was removed and the salivary glands placed in a microfuge tube containing saline and a broad-spectrum proteinase inhibitor (Sigma). Pairs of labial salivary glands from four caterpillars were pooled and homogenized in Nathanson's saline with proteinase inhibitor. The homogenate was centrifuged and the supernatant filtered using $0.22 \mu \mathrm{m}$ low protein binding membrane filters (Millipore). The GOX activity of the soluble homogenate was assayed using the $o$-dianisidine-horseradish peroxidase assay (Bergmeyer, 1974). A reaction cocktail containing $10 \% \beta$-D-glucose, $0.0066 \% o$-dianisidine in $0.1 \mathrm{M}$ potassium phosphate buffer, $\mathrm{pH} 7.0$ was brought to $35^{\circ} \mathrm{C}$. The salivary gland homogenate and horseradish peroxidase (final concentration $3 \mathrm{U}$; Sigma) were added to the reaction cocktail and GOX activity was measured in duplicate spectrophotometrically at $460 \mathrm{~nm}$. Controls included all reaction compounds except for the salivary gland extract (blank) and boiled homogenate (negative control). Fungal GOX (Sigma) was used as a positive control. Enzyme activity in 6-8 biological replicates of pooled labial salivary glands was analyzed.

For all salivary gland homogenates, total proteins was also measured by solubilizing the salivary gland pellet in $1 \mathrm{M} \mathrm{NaOH}$ and heating at $50^{\circ} \mathrm{C}$. Samples were cooled to room temperature and protein levels determined by the Bradford method (Bradford, 1976) according to the manufacturer's instructions (Sigma) using bovine serum albumin as the protein standard.

\subsubsection{Experiment 2}

Early instar caterpillars took longer to develop on the nutrient-poor 22p:20c. Therefore, in this subsequent experiment, caterpillars were reared on a meridic wheat germ-based diet (Bio-Serv) and then transferred individually during the 3 rd instar to a chemically defined diet which contained the same glucose levels but ranged in $\mathrm{P}$ content (33p:30c, $15 \mathrm{p}: 30 \mathrm{c}$, or $5 \mathrm{p}: 30 \mathrm{c})$. The amount of diets eaten was not determined. Salivary glands were dissected from mid-4th instar caterpillars since these instars had high GOX activities and assayed for GOX activity as outlined above (Section 2.7.1). A diet-dependent effect on caterpillar biomass was not seen (average mass $=0.079 \pm 0.006 \mathrm{~g}$; $\left.F_{(2,135)}=0.056, p=0.95\right)$. To determine if $\mathrm{P}$ level affected the level of salivary proteins, soluble labial salivary protein levels were measured by the Bradford assay (Bradford, 1976) as described above. Six to eight biological replicates of pooled pairs of labial salivary glands were analyzed for each diet.

\subsection{Statistical analyses}

Statistical analyses were performed using SPSS version 14 (SPSS Inc., Chicago, IL). Diet consumption and performance of caterpillars surviving until pupation were analyzed using general linear models, in particular, analysis of variance (ANOVA), analysis of covariance (ANCOVA) and multiple analysis of covariance (MANCOVA). Statistical differences were determined by Tukey post-hoc tests. Significant differences $(p \leqslant 0.05)$ are indicated in graphs and tables by different alphabetical letters. Caterpillar survivorship was analyzed by Fisher's exact test.

\section{Results}

\subsection{Nutrient intake and performance}

Previous studies have shown that $S$. exigua caterpillars select an intake target of 22p:20c (Merkx-Jacques et al., in press). On P-biased and C-biased diets, caterpillar face nutritional excesses (Fig. 1) (Lee et al., 2002, 2006; Raubenheimer and Simpson, 1999; Waldbauer et al., 1984).

A survival of greater than $86 \%$ was observed, irrespective of diet (Fisher's exact test, $p=0.39$ ) (Fig. 2A). Caterpillars took longer to reach pupation on the Cbiased, P-poor diets (two-way ANOVA, $F_{(3,108)}=17.417$, $p<0.001$ ) (Fig. 2B). Supernumerary 6th instar caterpillars were occasionally observed on all diets. The pupal biomass attained by these caterpillars restricted to the different foods was not statistically different (two-way ANOVA, $\left.F_{(3,108)}=0.683, p=0.565\right)$. Caterpillar gender did not significantly effect the nutritional or performance criteria which were assessed in this study (total food consumption: $F_{(1,108)}=0, p=0.99$; consumption rate: $F_{(1,108)}=0.20$, $p=0.89$; development time: $F_{(1,105)}=0.17, p=0.69$; pupal biomass: $\left.F_{(1,108)}=0.17, p=0.69\right)$.

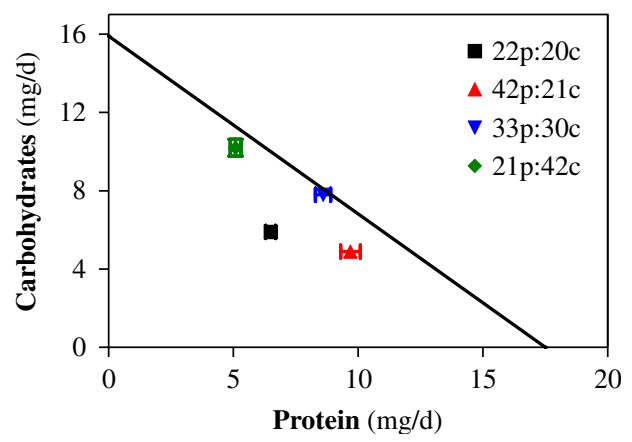

Fig. 1. Nutrient consumption rate of Spodoptera exigua caterpillars reared on defined, artificial diet. In no-choice experiments, 2nd instar caterpillars were restricted to a single food (nutrient concentration $42 \%$ : $22 \mathrm{p}: 20 \mathrm{c}$; nutrient concentration 66\%: $\boldsymbol{\Delta}$ 42p:21c, $\boldsymbol{\nabla}$ 33p:30c, $-21 \mathrm{p}: 42 \mathrm{c})$ until pupation. Bivariate means represent the average protein and carbohydrate ingestion $(\mathrm{mg})$ of $25-30$ insects per day \pm S.E. 


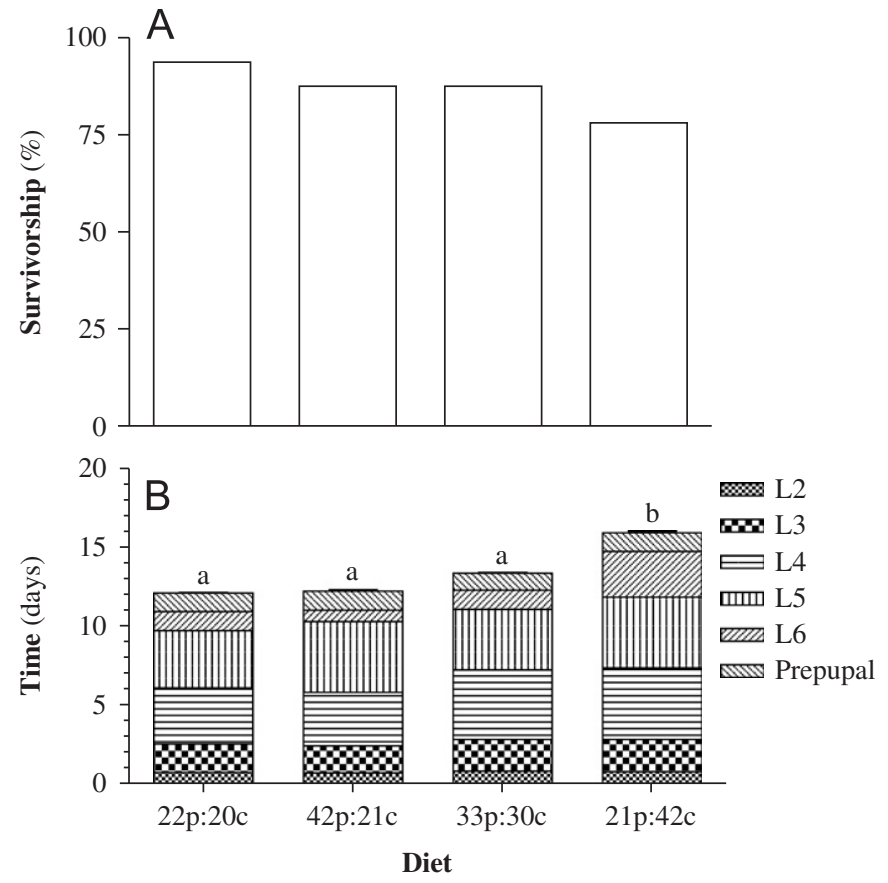

Fig. 2. Survival and development of Spodoptera exigua caterpillars reared on defined, artificial diets. In no-choice experiments, 2nd instar caterpillars were restricted to a single food (nutrient concentration $42 \%$ : $22 \mathrm{p}: 20 \mathrm{c}$, nutrient concentration 66\%: 42p:21c, 33p:30c, 21p:42c) until pupation. (A) Survival: bars represent the mean survival of 32 initial insects (Pearson $\left.\chi_{(3,127)}^{2}=3.459, p=0.326\right)$. (B) Stadium duration: bars represent the mean time (days) for 2 nd instar caterpillars to reach pupation (25-28 insects \pm S.E. Stadium duration was calculated from observations at $12 \mathrm{~h}$ intervals. Supernumary 6 th instar was occasionally observed. Significant differences in caterpillar development are indicated by alphabetical letters (Tukey post-hoc tests, $p<0.05$ ).

\subsection{Carbohydrate utilization}

Pupal lipid reserves are strongly dependent on diet (ANOVA, $\left.F_{(3,93)}=26.2, p<0.001\right)$, with the most lipid stores accumulated on C-biased diets. When the total amount of $\mathrm{C}$ eaten is taken into account (covariate), the slopes of the lines indicates that caterpillars on the P-biased diets have a greater efficiency of converting carbohydrates from the diet into lipid reserves (ANCOVA, covariate: total C: $\left.F_{(1,84)}=159.5, p<0.001\right)$ (Fig. 3A). When the total amount of $\mathrm{C}$ eaten is compared to the assimilate or egested $\mathrm{C}$ (Fig. 3B and C), it is apparent that caterpillars on Cbiased diets are egesting excess carbohydrates such that when the relationship between diet and pupal lipids is assessed, taking into account the amount of assimilated carbohydrates, a significant relationship is not observed (ANCOVA, covariate: $\mathrm{C}$ assimilated: $F_{(1,93)}=1.9, p=$ 0.174) (Fig. 3D). On three diets (22p:20c, 33p:30c, and 42p:21c) caterpillars are obtaining sufficient carbohydrates and targeting lipid stores of between $\sim 20-30 \mathrm{mg}$. Caterpillars on the P-biased diet (42p:21c) attain these pupal lipid amounts only when they are able to assimilate $\sim 50 \mathrm{mg}$ of carbohydrates. These findings suggest that caterpillars on the P-biased diet are efficient at $\mathrm{C}$ utilization and insects restricted to the C-biased diets have preand/or post-ingestive mechanisms for disposing of excess carbohydrates.

Insect gender did not effect the amount of carbohydrates eaten or retained or the accumulation of pupal lipid stores (C ingestion: $F_{(1,95)}=0.11, p=0.74 ; \mathrm{C}$ retention: $F_{(1,39)}=$ $1.85, p=0.18$; pupal lipids: $\left.F_{(1,95)}=0.57, p=0.45\right)$.

\subsection{Caterpillar labial salivary glucose oxidase activity}

\subsubsection{Experiment 1}

The activity of caterpillar labial salivary GOX was significantly affected by diet (U/LSG: $F_{(3,23)}=14.017$, $p<0.001 ; \mathrm{U} / \mathrm{mg} \times$ pair $\left.\mathrm{LSG}: F_{(3,23)}=14.319, p<0.001\right)$ (Fig. 4); this appears to reflect the $\mathrm{P}$ level of the food. In terms of total activity (U/pair LSG) or activity per milligram soluble protein $(\mathrm{U} / \mathrm{mg} \times$ pair $\mathrm{LSG})$, a significant difference in GOX activity was not observed between caterpillars on diets with comparable protein levels (22p:20c vs. 21p:42c). Instead, the highest salivary GOX activity was found in caterpillars transferred to $42 \mathrm{p}: 21 \mathrm{c}$.

\subsubsection{Experiment 2}

In the previous experiment, dietary protein appeared to affect labial salivary GOX activity, but this was difficult to conclusively determine since carbohydrate levels were also changing. In this experiment, 3rd instar caterpillars fed for a shorter time on a chemically defined diet which had the same glucose composition $(30 \%)$ but differed in protein levels $(5 \%, 15 \%$, or $33 \%)$. Diet significantly affected the activity of caterpillar labial salivary GOX (U/LSG: $\left.F_{(2,17)}=43.46, p<0.001\right) \quad($ Fig. $5 \mathrm{~A})$, with the highest activity associated with caterpillars feeding on the P-rich diet (33p:30c). Soluble protein levels in the labial salivary gland of these caterpillars were also significantly higher on the P-rich diet $\left(\mathrm{mg} / \mathrm{LSG}: F_{(2,17)}=24.21, p<0.001\right)$ (Fig. 5B).

\subsection{Frass carbohydrate composition}

Caterpillar frass was analyzed for glucose and gluconate: two possible glucose-associated excretion products. Gender did not effect frass glucose or gluconate levels (glucose: $F_{(1,46)}=0.32, p=0.58$; gluconate: $\left.F_{(1,53)}=0.63, p=0.43\right)$. Frass glucose levels increased with the digestible $\mathrm{C}$ content of the diet (total glucose $(\mathrm{mg}): F_{(3,46)}=53.349, p<0.001$; Glucose/frass $\left.\quad(\mathrm{mg} / \mathrm{mg}): \quad F_{(3,46)}=77.900, \quad p<0.001\right)$ (Fig. 6A). In comparison, frass gluconate was only present at low levels and varied slightly between treatments (twoway ANOVA, $F_{(3,53)}=2.944, p=0.043$ ) (Fig. 6B). Cellulose, gluconate and glucose account for the dry weight of the frass from caterpillars reared on the C-biased diet (Fig. 6C). In comparison, caterpillars reared on equalratio and P-biased diets also egest a small percentage of unknown components, which presumably contains protein and/or amino acid metabolites. 
A

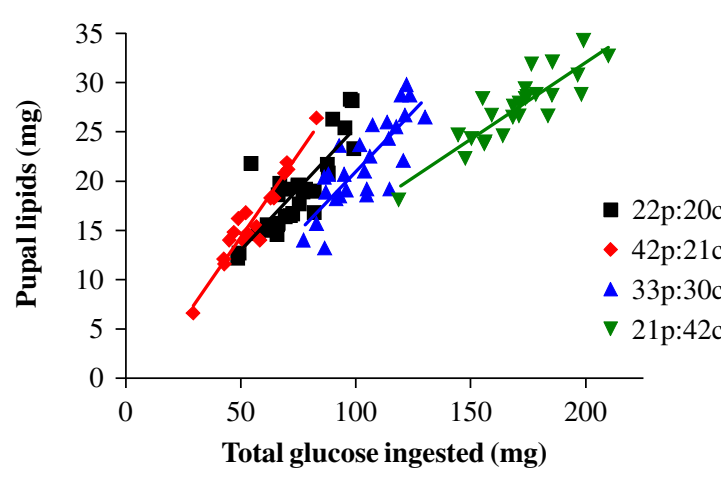

C

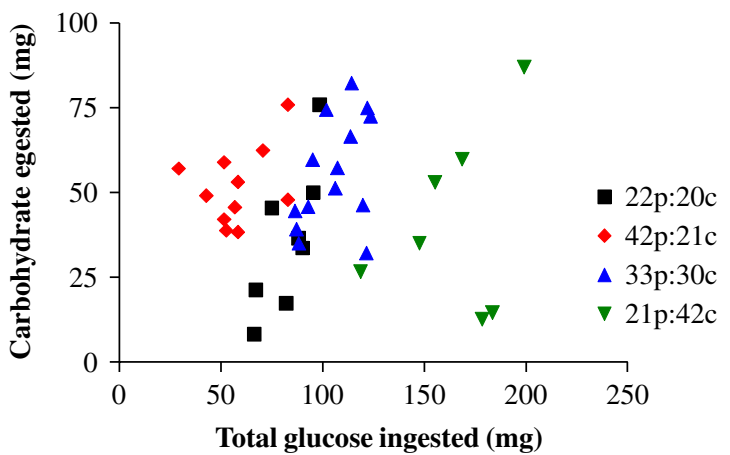

B

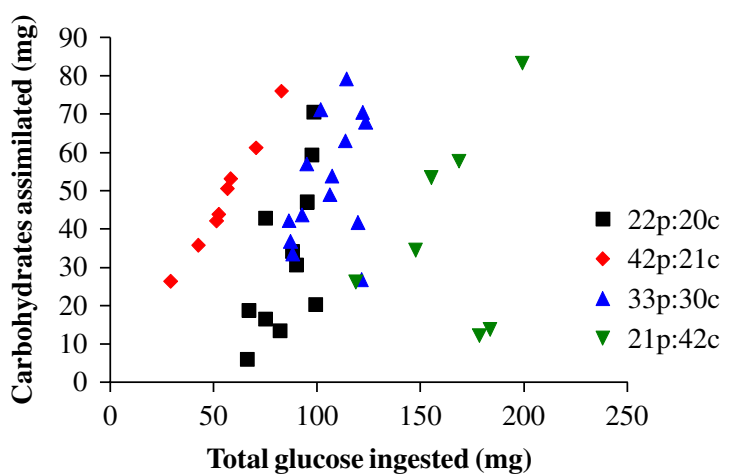

D

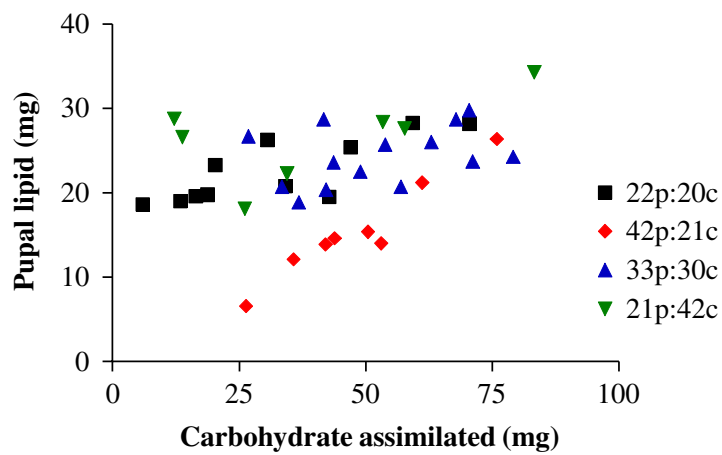

Fig. 3. Pupal lipid content and lipid conversion efficiency. 2nd instar Spodoptera exigua caterpillars were restricted to a single food (nutrient concentration 42\%: 22p:20c; nutrient concentration 66\%: $\boldsymbol{\Delta}$ 42p:21c, $\boldsymbol{\nabla} 33 \mathrm{p}: 30 \mathrm{c},-21 \mathrm{p}: 42 \mathrm{c}$ ) until pupation. (A) Conversion of total ingested carbohydrates into pupal lipids: scatterplot illustrates the relationship between pupal lipid accumulation and total digestible carbohydrate ingested by caterpillars restricted to different diets. (B) Digestible carbohydrates assimilated: scatterplot illustrates the relationship between the amount of digestible carbohydrates eaten and retained by caterpillars restricted to different diets. (C) Carbohydrate retention: scatterplot illustrates the relationship between the amount of glucose ingested and the carbohydrates egested by caterpillars restricted to different diets. (D) Conversion of assimilated carbohydrates into pupal lipids: scatterplot illustrates the relationship between the amount of digestible carbohydrates retained by caterpillars restricted to different diets and their pupal lipid reserves.

\section{Discussion}

Previous studies have shown that the self-selected nutrient intake ratio for $S$. exigua caterpillars is a slightly P-biased diet (22p:20c, 42\%) (Merkx-Jacques et al., in press). In this study, we wanted to evaluate caterpillar coping strategies when restricted to diets containing nutritional excesses, specifically to determine if salivary GOX may be a mechanism for the caterpillar to cope with excess dietary carbohydrates. Therefore, $S$. exigua caterpillar performance was assessed on a range of diets which had higher nutritional concentrations $(63 \%)$ were compared to this self-selected diet. This is consistent with plant nutrient content which commonly ranges from $40 \%$ to $66 \%$ with typical P:C values for the foliage of herbaceaous dicots in the range between $10-16 \% \mathrm{P}$ and 40-45\% C (National Research Council, 2001; Yeoh et al., 1992).

It was unexpected that $S$. exigua caterpillars did show evidence of compensatory feeding when restricted to the dilute diet (22p:20c vs. 30p:30c) as has been observed for other closely related Spodoptera caterpillar species (Lee et al., 2004a, b; Wheeler and Slansky, 1991). We speculate that the reason for this is that even though $22 \mathrm{p}: 20 \mathrm{c}$ has roughly $66 \%$ of the nutritive value of $30 \mathrm{p}: 30 \mathrm{c}$, it still has satisfactory dietary value, compared to the extremely dilute samples used in previous studies (i.e. 8.4p:8.4c) (Lee et al., 2004b).

On C-biased, P-poor diets, $S$. exigua caterpillars must still attain sufficient protein resources for growth and development. Therefore, in this and other studies, longer developmental stadia are observed on these diets (Fig. 2B) (Despland and Noseworthy, 2006; Lee et al., 2002, 2003, 2004a, 2006; Manuwoto and Scriber, 1985; Petersen et al., 2000; Raubenheimer et al., 2005; Telang et al., 2001; Thompson et al., 2005; Waldbauer et al., 1984; Whitford et al., 1992). Supernumerary 6th instar caterpillars are observed on all diets; however, more caterpillars required an additional instar to attain proper resources on the P-poor diet.

In S. exigua, pupal biomass, which strongly reflects lipid reserves, is positively and closely correlated with adult female egg production (Tisdale and Sappington, 2001). In a previous study, a diet-dependent difference in $S$. exigua pupal biomass and lipid reserves was not observed (Merkx-Jacques et al., in press). This suggested that 


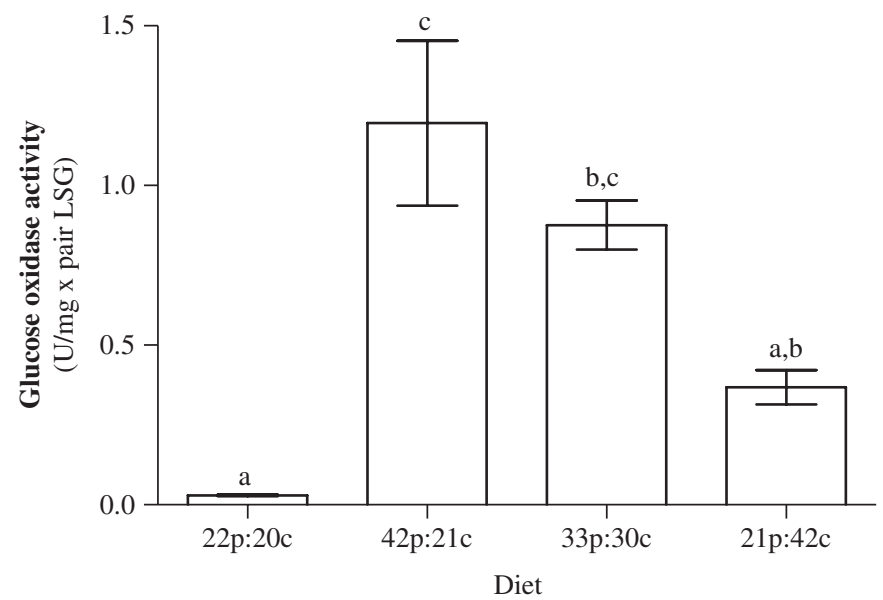

Fig. 4. Effect of protein to digestible carbohydrate ratio (P:C) diet on Spodoptera exigua caterpillar labial salivary glucose oxidase (GOX) activity. (A) Caterpillars were reared on their self-selected diet of 22p:20c (Merkx-Jacques et al., in press) until the 3rd instar and then switched to a defined food (nutrient concentration $42 \%: 22 \mathrm{p}: 20 \mathrm{c}$; nutrient concentration $66 \%$ : 42p:21c, 33p:30c, 21p:42c). Pairs of labial salivary glands (LSG) were removed from actively feeding 5 th instar caterpillars, pooled and assayed for GOX activity and protein content. Bars represent the mean LSG GOX activity per $\mathrm{mg}$ protein \pm S.E. of six replicates. Samples below the assay detection limit were not included in the calculations of GOX activity. Significant differences in GOX activity are represented by different alphabetical lettering (Tukey post-hoc tests, $p<0.05)$.

caterpillars on the C-poor diet had efficient mechanisms to process carbon skeletons from excess amino acids. In this experiment where caterpillars were reared on diets with a higher nutritional concentration, a food-dependent difference in pupal biomass was not observed but higher pupal lipid reserves were found in caterpillars reared on the C-rich diets (Fig. 3A). Similar findings were observed in studies with related Spodoptera species where pupal lipid stores increase when caterpillars are reared on a C-rich diet compared with those on the P-rich, C-poor diets (Lee et al., 2002, 2003, 2004a, b). Nonetheless, the amount of lipid stored relative to carbohydrate consumed was higher on P-biased foods, confirming that the efficiency of carbohydrate metabolism increases with P-bias of the diet (Fig. 3A).

Caterpillars on the C-biased diets egested more glucose (Fig. 6C), leading to similar values for carbohydrate assimilation, despite differences in consumption on different diets (Fig. 3B and C). These findings suggest a pre-absorptive mechanism for $\mathrm{C}$ regulation, where excess glucose is voided directly in the frass. This contrasts with previous observations with hemimetabolous locusts, where higher carbohydrate assimilation was observed on C-limited diets and locusts voided excess carbohydrates post-ingestively by increasing their respiration (Zanotto et al., 1993). In this study, we were interested in determining if a pre-ingestive mechanism of $\mathrm{C}$ regulation, such as the use of salivary enzymes, may occur in addition to mechanisms such as the elevation of respiration rate.
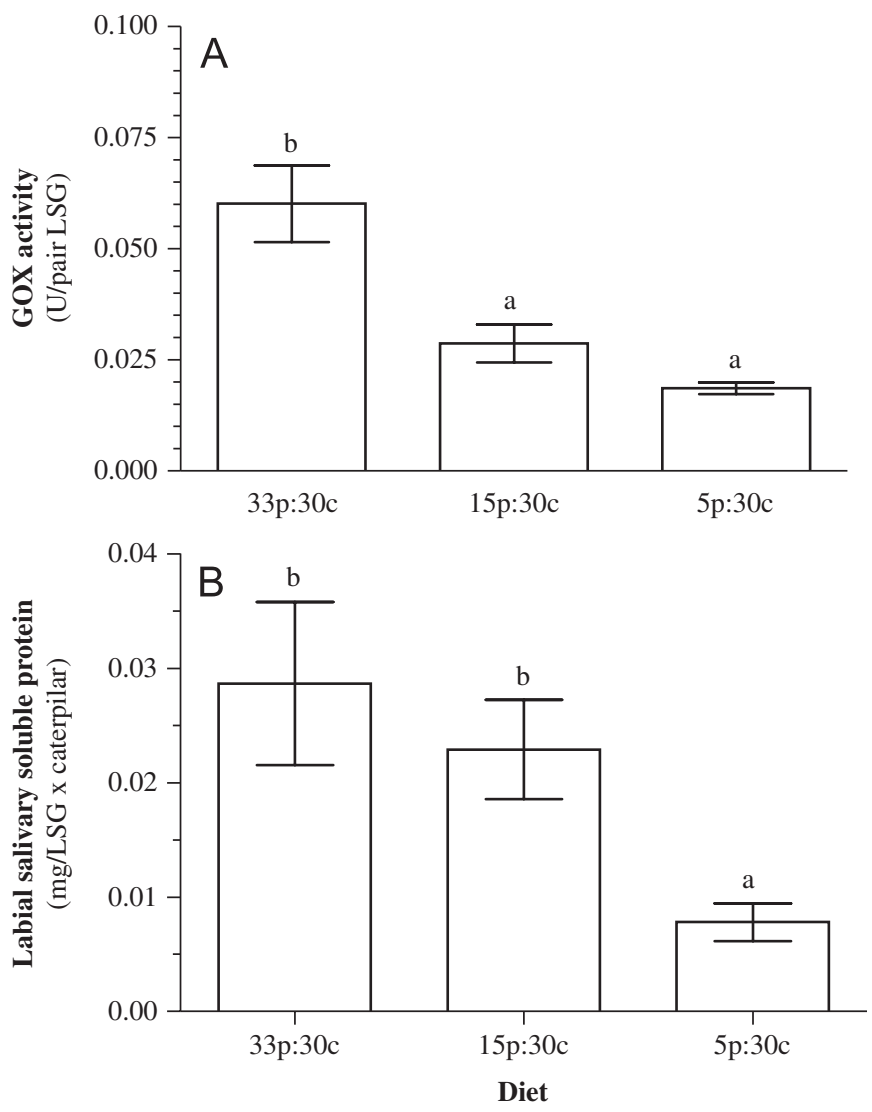

Fig. 5. Effect of dietary protein on Spodoptera exigua caterpillar labial salivary glucose oxidase (GOX) activity. Caterpillars were reared on a meridic wheat germ-based Bio-Serv diet until the 3rd instar and then switched to a defined food (5p:30c, 15p:30c, 33p:30c). (A) Labial salivary GOX activity: pairs of labial salivary glands (LSG) were removed from actively feeding 4th instar caterpillars, pooled and assayed for GOX activity. Bars represent the mean LSG GOX activity per caterpillar \pm S.E. of six replicates. (B) Soluble protein: bars represent mean soluble protein per $L S G \pm$ S.E. of six replicates. Significant differences are represented by different alphabetical lettering (Tukey post-hoc tests, $p<0.05$ ).

Labial salivary GOX is a digestive enzyme produced and secreted through the spinneret onto leaf material by many Noctuid caterpillar species (Eichenseer et al., 1999; MerkxJacques and Bede, 2005; Zong and Wang, 2004). Recently, there has been speculation as to the biological role of this enzyme, particularly since its activity appears to be regulated by diet (Merkx-Jacques and Bede, 2005; Peiffer and Felton, 2005). GOX catalyzes the oxidation of glucose to gluconate, making carbohydrates inaccessible to the caterpillar. Gluconate was identified in caterpillar frass (Fig. 6B), albeit at low levels, indicating that GOX is involved in the conversion of glucose to gluconate which is egested. These levels probably do not represent actually enzyme conversion since, though non-accessible to insects, gluconate is an important carbon source for some bacteria, including many gut-associated Enterobacteria, such Escherichia coli (Chang et al., 2004; Peekhaus and Conway, 1998; Portais and Delort, 2002).

Therefore, secretion of GOX may be a strategic adaptation of generalist caterpillars to oxidize excess 

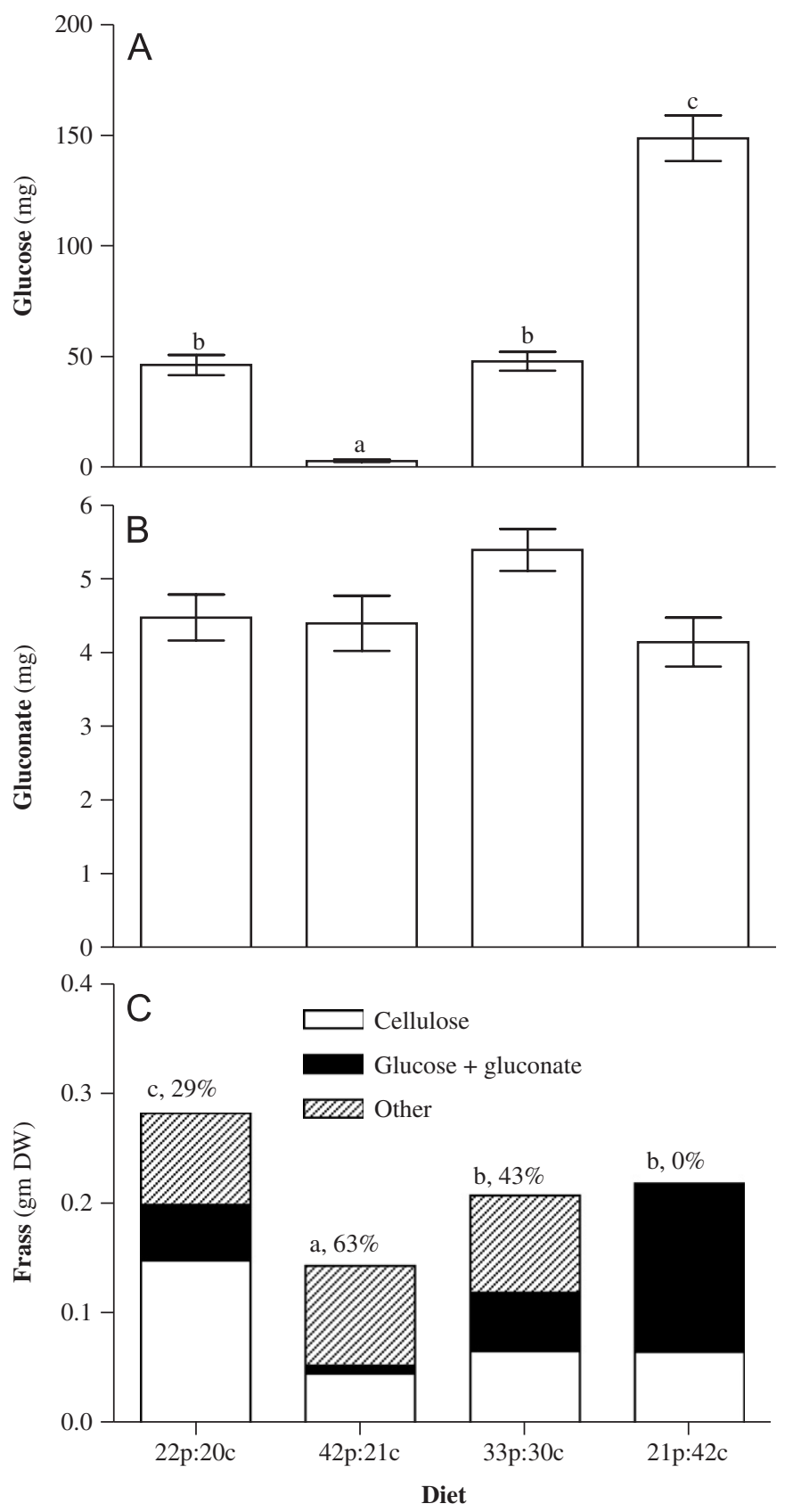

Fig. 6. Frass levels of glucose and its metabolite gluconate. Spodoptera exigua caterpillars were reared until pupation on chemically defined diets (nutrient concentration 42\%: 22p:20c; nutrient concentration $66 \%$ : $42 \mathrm{p}: 21 \mathrm{c}, 33 \mathrm{p}: 30 \mathrm{c}, 21 \mathrm{p}: 42 \mathrm{c})$ containing glucose as the sole source of digestible carbohydrates. The digestible carbohydrate source in the food was glucose which can be metabolized by labial salivary glucose oxidase to gluconate. Total frass collected from these caterpillars were analyzed for (A) glucose and its metabolite (B) gluconate: bars represent the mean metabolite level $(\mathrm{mg}) \pm$ S.E. for 9-21 individuals. Significant differences are indicated by different alphabetical lettering (Tukey post-hoc tests, $p<0.05$ ). (C) Frass metabolite levels: bars represent the mean frass egested \pm S.E. for 15 caterpillars. Frass contains cellulose, glucose and gluconate and unaccounted for metabolites, which are presumably proteins and catabolic products. Significant differences in frass egested are indicated by different alphabetical lettering (Tukey post-hoc tests, $p<0.05$ ). Percentages represent the proportion of the frass composed of unaccounted, presumably nitrogen-based metabolites. dietary carbohydrates that they may encounter. Based on this hypothesis, we expected labial salivary GOX to reflect the digestible carbohydrate content of the diet and be highest on sugar-rich sources. Instead, there was a strong relationship between dietary protein content and GOX activity. Labial salivary GOX activity (U/mg $\times$ pair LSG) was over three-fold higher in caterpillars transferred to the protein-rich (42p:21c) than the carbohydrate-rich (21p:42c) diet (Fig. 4). When the C-content of the diet was held constant, GOX activity was associated with high $\mathrm{P}$ content and an overall increase in soluble salivary proteins were observed (Fig. 5A and B). This implies that on proteinlimited diets, S. exigua caterpillars may be "unwilling" to synthesize excess digestive enzymes which are secreted into the environment, resulting in a loss of nitrogen which is already limiting.

Findings from this study seem to imply that GOX is not a metabolic strategy to cope with excess carbohydrates. On the C-limited, P-rich diet, $\mathrm{C}$ utilization efficiency was increased (Fig. 3A) and on the C-rich diets, caterpillars coped with glucose excesses by increasing $\mathrm{C}$ egestion. However, nutrient utilization by caterpillars reared on a P-biased diet (42p:21c) with those reared on their intake target (22p:20c) is worth focusing attention on. On a daily basis, caterpillars reared on these diets ingested similar amounts of digestible carbohydrates (Fig. 1) and reached similar performance in terms of mortality, development, pupal lipid stores and pupal biomass (Fig. 2A and B). Yet, caterpillars on the P-biased diet, which had higher salivary GOX activity, had less glucose egested in the frass (Fig. 6A); this undoubtedly reflects the increased $\mathrm{C}$ utilization efficiency of these caterpillars, but, perhaps, also supports the notion the caterpillar salivary GOX does indeed metabolize excess glucose, but much of the gluconate produced is metabolized by gut-associated bacteria.

\subsection{Ecological implications}

Understanding how caterpillars mediate feeding decisions and nutrient utilization and, hence, the regulation of GOX activity, is not only important from both ecological and pest management viewpoints, but also because salivary GOX has also been implicated in subverting plant defense responses (Musser et al., 2002, 2005). The hydrogen peroxide produced by this enzyme activity is believed to act as a signaling molecule and acts to attenuate octadecanoid- or ethylene-mediated plant defense responses (Beckers and Spoel, 2006; Shoji et al., 2000; Winz and Baldwin, 2001).

This study indicates that caterpillar labial salivary GOX activity is closely correlated with dietary protein intake. Martin (1991) proposed that for the insect, it is not advantageous to produce enzymes involved in complex carbohydrate digestion, such as cellulases which degrade the cellulose polymers to glucose sugars, since the plant provides sufficient carbohydrate resources and protein is 
clearly limiting to phytophagous insects. Similarly, when feeding on most plant tissues, generalist caterpillars are faced with a C-biased diet and must weigh the detrimental effects of dietary C-excess with P-limitations (Merkx-Jacques et al., in press; Raubenheimer et al., 2005). When the caterpillar has ingested sufficient $P$, then salivary GOX might be produced and secreted to act either as a strategy to attenuate plant induced defenses or a preingestive mechanism to cope with excess dietary C (Bede et al., 2007; Musser et al., 2002).

In many studies, caterpillars show better performance on heavily fertilized plants (Al-Zubaidi and Capinera, 1983; Goverde and Erhardt, 2003; Manuwoto and Scriber, 1985; Wheeler et al., 1998). Even though nitrogen-based plant defense might be strengthened on nitrogen-fertilized crops (Fritz et al., 2006), the increased quantity and quality of foliar protein levels often result in shorter developmental times, higher pupal weight and egg production (Throop et al., 2004). P-biased tissues, such as anthers or young photosynthetic leaves, or heavily nitrogen-fertilized plants, benefit the caterpillar herbivore by contributing the building blocks for growth, development and reproduction. As well, dietary P may influence salivary enzyme activity, producing GOX, which may function to regulate excess $\mathrm{C}$ and/or as a strategy to circumvent induced plant defenses (Musser et al., 2002, 2005).

\section{Acknowledgments}

We thank Jeremy McNeil and Steve Simpson for insightful comments on an earlier version of this manuscript. This research was funded through an NSERC operating grant and CFI infrastructure grant to J.C.B.

\section{References}

Al-Zubaidi, F.S., Capinera, J.L., 1983. Application of different nitrogen levels to the host plant and cannibalistic behaviour of the beet armyworm, Spodoptera exigua (Hübner) (Lepidoptera: Noctuidae). Environmental Entomology 12, 1687-1689.

Auger, M., 1995. Low nutritive quality as a plant defense - effects of herbivore-mediated interactions. Evolutionary Ecology 9, 605-616.

Awmack, C.S., Leather, S.R., 2002. Host plant quality and fecundity in herbivorous insects. Annual Review of Entomology 47, 817-844.

Bae, H., Sicher, R., 2004. Changes of soluble protein expression and leaf metabolite levels in Arabidopsis thaliana grown in elevated atmospheric carbon dioxide. Field Crops Research 90, 61-73.

Barton-Browne, L., 1993. Physiologically induced changes in resourceoriented behaviour. Annual Review of Entomology 38, 1-25.

Beckers, G.J.M., Spoel, S.H., 2006. Fine-tuning plant defense signalling: salicylate versus jasmonate. Plant Biology 8, 1-10.

Bede, J.C., Musser, R.O., Felton, G.W., Korth, K.L., 2006. Caterpillar herbivory and salivary enzymes decrease transcript levels of Medicago truncatula genes encoding early enzymes in terpenoid biosynthesis. Plant Molecular Biology 60, 519-531.

Bede, J.C., McNeil, J.N., Tobe, S.S., 2007. The role of neuropeptides in caterpillar nutritional ecology. Peptides 28, 185-196.

Behmer, S.T., Simpson, S.J., Raubenheimer, D., 2002. Herbivore foraging in chemically heterogeneous environments: nutrients and secondary metabolites. Ecology 83, 2489-2501.
Bergmeyer, H.U., 1974. Reagents for enzymatic analysis. In: Bergmeyer, H.U., Gawehn, K. (Eds.), Methods of Enzymatic Analysis, vol. 1. Verlag Chemie, Weinheim, pp. 494-495.

Bernays, E.A., Singer, M.S., Rodrigues, D., 2004. Foraging in nature: foraging efficiency and attentiveness in caterpillars with different diet breadths. Ecological Entomology 29, 389-397.

Bradford, M.M., 1976. Rapid and sensitive method for quantitation of microgram quantities of protein utilizing the principle of protein-dye binding. Analytical Biochemistry 72, 248-254.

Chang, D.-E., Smalley, D.J., Tucker, D.L., Leatham, M.P., Norris, W.E., Stevenson, S.J., Anderson, A.B., Grissom, J.E., Laux, D.C., Cohen, P.S., Conway, T., 2004. Carbon nutrition of Escherichia coli in the mouse intestine. Proceedings of the National Academy of Sciences 101, 7427-7432.

Chen, H., Wilkerson, C.G., Kuchar, J.A., Phinney, B.S., Howe, G.A., 2005. Jasmonate-inducible plant enzymes degrade essential amino acids in the herbivore gut. Proceedings of the National Academy of Sciences USA 102, 19237-19242.

Christensen, T.A., Itagaki, H., Teal, P.E.A., Jasensky, R.D., Tumlinson, J.H., Hildebrand, J.G., 1991. Innervation and neural regulation of the sex pheromone gland in female Heliothis moths. Proceedings of the National Academy of Sciences 88, 4971-4975.

Cross, J.M., von Korff, M., Altman, T., Bartzetko, L., Sulpice, R., Gibon, Y., Palacios, N., Stitt, M., 2006. Variation of enzyme activities and metabolite levels in 24 Arabidopsis accessions growing in carbonlimited conditions. Plant Physiology 142, 1574-1588.

Despland, E., Noseworthy, M., 2006. How well do specialist feeders regulate nutrient intake? Evidence from a gregarious tree-feeding caterpillar. The Journal of Experimental Biology 209, 1301-1309.

Eichenseer, H., Mathews, M.C., Bi, J.L., Murphy, J.B., Felton, G.W., 1999. Salivary glucose oxidase: multifunctional roles for Helicoverpa zea. Archives of Insect Biochemistry and Physiology 42, 99-109.

Felton, G.W., 1996. Nutritive quality of plant protein: sources of variation and insect herbivore responses. Archives of Insect Biochemistry and Physiology 32, 107-130.

Fritz, C., Palacios-Rojas, N., Feil, R., Stitt, M., 2006. Regulation of secondary metabolism by the carbon-nitrogen status in tobacco: nitrate inhibits large sectors of phenylpropanoid metabolism. Plant Journal 46, 533-548.

Goverde, M., Erhardt, A., 2003. Effects of elevated $\mathrm{CO}_{2}$ on development and larval food-plant preference in the butterfly Coenonympha pamphilus (Lepidoptera, Satyridae). Global Change Biology 9, 74-83.

Hägele, B.F., Rowell-Rahier, M., 1999. Dietary mixing in three generalist herbivores: nutrient complementation or toxin dilution. Oecologia 119, 521-533.

Kang, J.-H., Wang, L., Giri, A., Baldwin, I.T., 2006. Silencing threonine deaminase and JAR4 in Nicotiana attenuata impairs jasmonic acidisoleucine-mediated defenses against Manduca sexta. Plant Cell 18, 3303-3320.

Karowe, D.N., Martin, M.M., 1989. The effects of quantity and quality of diet nitrogen on the growth, efficiency of food utilization, nitrogen budget and metabolic rate of fifth instar Spodoptera eridania larvae (Lepidoptera: Noctuidae). Journal of Insect Physiology 35, 699-708.

Lee, K.P., Behmer, S.T., Raubenheimer, D., Simpson, S.J., 2002. A geometric analysis of nutrient regulation in the generalist caterpillar Spodoptera littoralis (Boisduval). Journal of Insect Physiology 48, 655-665.

Lee, K.P., Raubenheimer, D., Behmer, S.T., Simpson, S.J., 2003. A correlation between macronutrient balancing and insect host-plant range: evidence from the specialist caterpillar Spodoptera exempta (Walker). Journal of Insect Physiology 49, 1161-1171.

Lee, K.P., Simpson, S.J., Raubenheimer, D., 2004a. A comparison of nutrient regulation between solitarious and gregarious phases of the specialist caterpillar Spodoptera exempta (Walker). Journal of Insect Physiology 50, 1171-1180.

Lee, K.P., Raubenheimer, D., Simpson, S.J., 2004b. The effects of nutritional imbalance on compensatory feeding for cellulose-mediated 
dietary dilution in a generalist caterpillar. Physiological Entomology 29, 108-117.

Lee, K.P., Behmer, S.T., Simpson, S.J., 2006. Nutrient regulation in relation to diet breadth: a comparison of Heliothis sister species and a hybrid. Journal of Experimental Biology 209, 2076-2084.

Manuwoto, S., Scriber, J.M., 1985. Differential effects of nitrogen fertilization of three corn genotypes on biomass and nitrogen utilization by the southern armyworm, Spodoptera eridania. Agriculture, Ecosystems and Environment 14, 25-40.

Martin, M.M., 1991. The evolution of cellulose digestion in insects. Philosophical Transactions Royal Society of London B 333, 281-288.

Mattson Jr., W.J., 1980. Herbivory in relation to plant nitrogen content. Annual Review Ecology and Systematics 11, 119-161.

Mayntz, D., Raubenheimer, D., Salomon, M., Toft, S., Simpson, S.J., 2005. Nutrient-specific foraging in invertebrate predators. Science 307, $111-112$.

McAuslane, H.J., Alborn, H.T., 2000. Influence of previous herbivory on behaviour and development of Spodoptera exigua larvae on glanded and glandless cotton. Entomologia Experimentalis et Applicata 97, 283-291.

Merkx-Jacques, M., Bede, J.C., 2005. Influence of diet on the larval beet armyworm, Spodoptera exigua, glucose oxidase activity. Journal of Insect Science 5, 48.

Merkx-Jacques, M., Despland, E., Bede, J.C., in press. Nutrient utilization by generalist caterpillars of the beet armyworm, Spodoptera exigua. Physiological Entomology XXX, XXX.

Moreau, G., Quiring, D.T., Eveleigh, E.S., Bauce, E., 2003. Advantages of a mixed diet: feeding on several foliar age classes increases the performance of a specialist herbivore. Oecologia 135, 391-399.

Musser, R.O., Hum-Musser, S.M., Eichenseer, H., Peiffer, M., Ervin, G., Murphy, J.B., Felton, G.W., 2002. Caterpillar saliva beats plant defences. Nature 416, 599-600.

Musser, R.O., Cipollino, D.F., Hum-Musser, S.M., Williams, S.A., Brown, J.K., Felton, G.W., 2005a. Evidence that the caterpillar salivary enzyme glucose oxidase provides herbivore offense in Solanaceous plants. Archives of Insect Biochemistry and Physiology $58,128-137$.

Musser, R.O., Kwon, H.S., Williams, S.A., White, C.J., Romano, M.A., Holt, S.M., Bradbury, S., Brown, J.K., Felton, G.W., 2005b. Evidence that caterpillar labial saliva suppresses infectivity of potential bacterial pathogens. Archives of Insect Biochemistry and Physiology 58, $138-144$.

National Research Council, 2001. Nutrient Requirements of Dairy Cattle. National Academy Press, Washington, DC.

Peekhaus, N., Conway, T., 1998. What's for dinner? Entner-Doudoroff metabolism in Escherichia coli. Journal of Bacteriology 180, 3495-3502.

Peiffer, M., Felton, G.W., 2005. The host plant as a factor in the synthesis and secretion of salivary glucose oxidase in larval Helicoverpa zea. Archives of Insect Biochemistry and Physiology 58, 106-113.

Petersen, C., Woods, H.A., Kingsolver, J.G., 2000. Stage-specific effects of temperature and dietary protein on growth and survival of Manduca sexta caterpillars. Physiological Entomology 25, 35-40.

Portais, J.-C., Delort, A.-M., 2002. Carbohydrate cycling in microorganisms: what can ${ }^{13} \mathrm{C}-\mathrm{NMR}$ tell us? FEMS Microbiology Reviews 26, 375-402.

Raubenheimer, D., Simpson, S.J., 1999. Integrating nutrition: a geometrical approach. Entomologia Experimentalis et Applicata 91, 67-82.

Raubenheimer, D., Simpson, S.J., 2003. Nutrient balancing in grasshoppers: behavioural and physiological correlates of dietary breadth. Journal of Experimental Biology 206, 1669-1681.

Raubenheimer, D., Lee, K.P., Simpson, S.J., 2005. Does Bertrand's rule apply to macronutrients. Proceedings of the Royal Society B 272, 2429-2434.

Ribeiro, J.M.C., 1995. Insect saliva: function, biochemistry, and physiology. In: Chapman, R.F., de Boer, G. (Eds.), Regulatory Mechanisms in Insect Feeding. Chapman \& Hall, New York, pp. $74-97$.
Roberts, M.R., Paul, N.D., 2006. Seduced by the dark side: integrating molecular and ecological perspectives on the influence of light on plant defence against pests and pathogens. New Phytologist 170, 677-699.

Roslin, T., Gripenberg, S., Salminen, J.P., Karonen, M., O'Hara, R.B., Pihlaja, K., Pulkkinen, P., 2006. Seeing the tree for the leaves-oaks as mosaics for a host-specific moth. Oikos 113, 106-120.

Roulston, T.H., Cane, J.H., Buchmann, S.L., 2000. What governs protein content of pollen: pollinator preferences, pollen-pistin interactions, or phylogeny? Ecological Monographs 70, 617-643.

Ryan, C.A., 1990. Protease inhibitors in plants: genes for improving defenses against insects and pathogens. Annual Review Phytopathology 28, 425-449.

Scoble, M.J., 1992. The Lepidoptera: Form, Function and Diversity. Oxford University Press, New York, USA.

Scriber, J.M., Slansky Jr., F., 1981. The nutritional ecology of immature insects. Annual Review Entomology 26, 183-211.

Shoji, T., Nakajima, K., Hashimoto, T., 2000. Ethylene suppresses jasmonate-induced gene expression in nicotine biosynthesis. Plant Cell Physiology 41, 1072-1076.

Simpson, S.J., Abisgold, J.D., 1985. Compensation by locusts for changes in dietary nutrients: behavioural mechanisms. Physiological Entomology $10,443-452$.

Simpson, S.J., Raubenheimer, D., 1993. The central role of the haemolymph in the regulation of nutrient intake in insects. Physiological Entomology 18, 395-403.

Simpson, S.J., Simpson, C.L., 1990. The Mechanisms of Nutritional Compensation by Phytophagous Insects. CRC press, Boca Raton.

Simpson, S.J., Sibly, R.M., Lee, K.P., Behmer, S.T., Raubenheimer, D., 2004. Optimal foraging when regulating intake of multiple nutrients. Animal Behaviour 68, 1299-1311.

Smits, P.H., van Velden, M.C., van de Vrie, M., Vlak, J.M., 1987. Feeding and dispersal of Spodoptera exigua larvae and its relevance for control with a nuclear polyhedrosis virus. Entomologia Experimentalis et Applicata 43, 67-72.

Telang, A., Booton, V., Chapman, R.F., Wheeler, D.E., 2001. How female caterpillars accumulate their nutrient reserves. Journal of Insect Physiology 47, 1055-1064.

Telang, A., Buck, N.A., Chapman, R.F., Wheeler, D.E., 2003. Sexual differences in postingestive processing of dietary protein and carbohydrate in caterpillars of two species. Physiological and Biochemical Zoology 76, 247-255.

Thompson, S.N., Redak, R.A., Wang, L.-W., 2005. Nutrition interacts with parasitism to influence growth and physiology of the insect Manduca sexta L. Journal of Experimental Biology 208, 611-623.

Throop, H.L., Holland, E.A., Parton, W.J., Ojima, D.S., Keough, C.A., 2004. Effects of nitrogen deposition and insect herbivory on patterns of ecosystem-level carbon and nitrogen dynamics: results from the CENTURY model. Global Change Biology 10, 1092-1105.

Tisdale, R.A., Sappington, T.W., 2001. Realized and potential fecundity, egg fertility and longevity of laboratory-reared female beet armyworm (Lepidoptera: Noctuidae) under different adult diet regimes. Annals of the Entomological Society of America 94, 415-419.

Waldbauer, G.P., Friedman, S., 1991. Self-selection of optimal diets by insects. Annual Review of Entomology 36, 43-63.

Waldbauer, G.P., Cohen, R.W., Friedman, S., 1984. Self-selection of an optimal nutrient mix from defined diets by larvae of the corn earworm, Heliothis zea (Boddie). Physiological Entomology 57, 590-597.

Warbrick-Smith, J., Behmer, S.T., Lee, K.P., Raubenheimer, D., Simpson, S.J., 2006. Evolving resistance to obesity in an insect. Proceedings of the National Academy of Sciences 103, 14045-14049.

Wheeler, G.S., Slansky, F., 1991. Compensatory response of the fall armyworm (Spodoptera frugiperda) when fed water- and cellulosediluted diets. Physiological Entomology 16, 361-374.

Wheeler, G.S., Van, T.K., Center, T.D., 1998. Fecundity and egg distribution of the herbivore Spodoptera pectinicornis as influenced by quality of the floating aquatic plant Pistia stratiotes. Entomologia Experimentalis et Applicata 86, 295-304. 
Whitford, F., Quisenberry, S.S., Moellenbeck, D.J., 1992. Nutritional response by rice and corn fall armyworm (Lepidoptera: Noctuidae) strains to dietary component substitution in artificial diets. Journal of Economic Entomology 85, 1491-1496.

Winz, R.A., Baldwin, I.T., 2001. Molecular interactions between the specialist herbivore Manduca sexta (Lepidoptera, Sphingidae) and its natural host Nicotiana attenuata. IV. Insect-induced ethylene reduces jasmonate-induced nicotine accumulation by regulating putrescine $N$-methyltransferase transcripts. Plant Physiology 125, 2189-2202.

Wright, G.A., Simpson, S.J., Raubenheimer, D., Stevenson, P.C., 2003. The feeding behaviour of the weevil, Exophthalmus jekelianus, with respect to the nutrients and allelochemicals in host plant leaves. Oikos $100,172-184$.

Yeoh, H.-H., Wee, Y.-C., Watson, L., 1992. Leaf protein contents and amino acid patterns of dicotyledonous plants. Biochemical Systematics and Ecology 20, 657-663.
Zanotto, F.P., Simpson, S.J., Raubenheimer, D., 1993. The regulation of growth by locusts through post-ingestive compensation for variation in the levels of dietary protein and carbohydrate. Physiological Entomology 18, 425-434.

Zanotto, F.P., Gouveia, S.M., Simpson, S.J., Raubenheimer, D., Calder, P.C., 1997. Nutritional homeostasis in locusts: is there a mechanism for increased energy expenditure during carbohydrate overfeeding? Journal of Experimental Biology 200, 2437-2448.

Zera, A.J., Mole, S., Rokke, K., 1994. Lipid, carbohydrate and nitrogen content of long- and short-winged Gryllus firmus: implications for the physiological cost of flight capability. Journal of Insect Physiology 40, 1037-1044.

Zong, N., Wang, C., 2004. Induction of nicotine in tobacco by herbivory and its relation to glucose oxidase activity in the labial gland of three noctuid caterpillars. Chinese Science Bulletin 2004, 1596-1601. 